\title{
A Short Survey on Fault Diagnosis of Rotating Machinery using Entropy Techniques
}

\author{
Zhiqiang $\mathrm{Huo}^{1,2}$, Yu Zhang ${ }^{1}$, and Lei Shu ${ }^{2,1}$ \\ 1 School of Engineering, University of Lincoln, Lincoln, UK, \\ ${ }^{2}$ Guangdong Provincial Key Laboratory on Petrochemical Equipment Fault \\ Diagnosis, \\ Guangdong University of Petrochemical Technology, Maoming, China, \\ \{zhuo, yzhang, lshu\}@lincoln.ac.uk
}

\begin{abstract}
Fault diagnosis is significant for identifying latent abnormalities, and implementing fault-tolerant operations for minimizing performance degradation caused by failures in industrial systems, such as rotating machinery. The emergence of entropy theory contributes to precisely measure irregularity and complexity in a time series, which can be used for discriminating prominent fault information in rotating machinery. In this short paper, the utilization of entropy techniques for fault diagnosis of rotating machinery is summarized. Finally, open research trends and conclusions are discussed and presented respectively.
\end{abstract}

Key words: Fault diagnosis, Rotating machinery, Entropy

\section{Introduction}

In recent decades, the world has witnessed a tremendous growth in the theory and practice of fault diagnostic approaches, which have been widely and successfully applied in fault diagnosis of rotating machinery, such as failure detection in rotors, rolling bearings and shafts. As a result, signal-based fault diagnosis has been a prominent technique to analyze non-linear and non-stationary signals. In this kind of diagnostic methods, feature extraction is one of the significant steps for characterizing fault information of interest in fault detection and identification. The traditional time-frequency domain parameters include peak value, mean value, root mean square (RMS), power spectrum, and RMS of the spectrum difference, etc. Apart from that, in the recent decade, entropy-based features have been applied extensively in the field of fault diagnosis by means of evaluating the irregularity and complexity in signals with different conditions.

\section{Fault Diagnosis based on Entropy Methods}

Entropy techniques can be considered as a powerful measurement tool that is capable of quantifying the irregularity in a time series. The occurrence of defects in rotating components usually produces subcritical frequencies and finally 


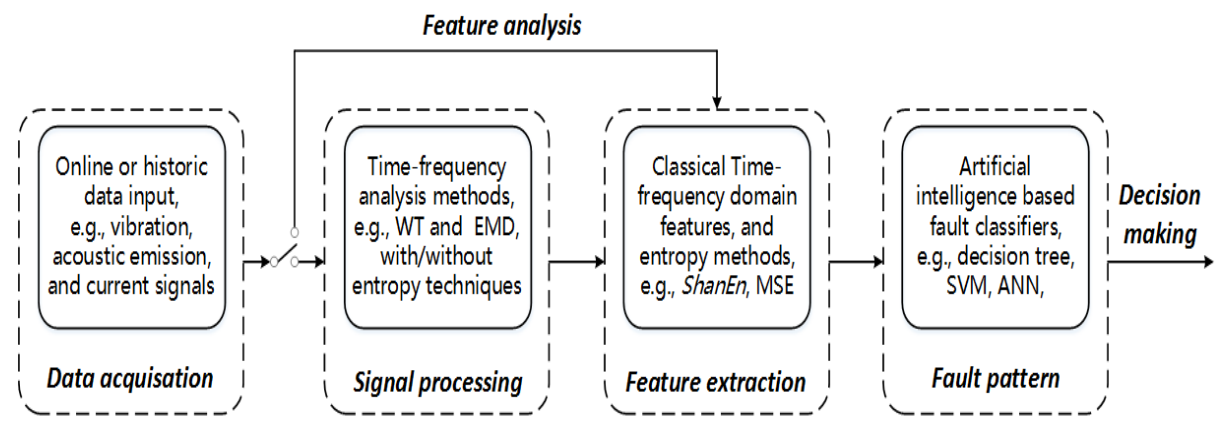

Fig. 1: Data flow of fault diagnosis of rotating machinery based entropy methods.

increases the amplitude of impulses in signals obtained from rotating machines, such as vibration and acoustic signals. According to literatures, the steps in fault diagnosis using entropy methods can be categorized into two main classes: 1) selection of multi-scale decomposed vectors obtained from multi-resolution analysis (MRA), such as wavelet transform (WT); 2) feature extraction of desired decomposed vectors or original signals. The traditional procedure of signal-based fault diagnosis using entropy methods is illustrated in Fig. 1. The most commonly used entropy features include power spectrum energy (PowerEn), Shannon entropy (ShanEn), approximate entropy ( $A p E n)$, sample entropy (SampEn), fuzzy entropy (FuzzyEn), permutation entropy (PerEn), and their corresponding multiple scale entropies.

\subsection{Single-scale Entropy Approaches}

PowerEn is one of useful tools that is adopted to describe how the energy of a signal or a time series is distributed within time domain [1], which can be defined as the absolute-value squared of the time series. ShanEn, named after Claude Shannon, was developed to solve the measurement problem of system's disorder in microscopic particle in information theory. Generally, PowerEn is applied together jointly with ShanEn to determine decomposed vectors obtained from MRA, such as wavelet coefficients and intrinsic mode functions (IMFs) obtained from WT and empirical mode decomposition (EMD) methods respectively. Later in 1990s, $A p E n$ was proposed by Pincus to determine changing complexity from data. Subsequently, SampEn and FuzzyEn, as a modification of ApEn were later developed to overcome the drawbacks that $A p E n$ subjected to, such as problems of small value obtained from short length of data and lack of relative consistency. To compare the effectiveness of ApEn, SampEn and FuzzyEn, comparative study was conducted in [2], where it was found that FuzzyEn yields more satisfying results when characterizing signals with different complexity. Similarly, PerEn [3] was also developed and applied as a measure of complexity. 


\subsection{Multiple-Scale Entropy Approaches (MEA)}

The concept of analyzing and measuring a time series from multiple scales was proposed by Costa, who proposed that the single-scale entropy algorithm yielded contradictory results when applied to real-world data sets obtained in health and disease states. On this basis, a variety of MEA methods have been proposed and widely applied in the field of fault diagnosis, such as multiscale entropy (MSE) [4], multiscale fuzzy entropy (MFE) [5], multiscale permutation entropy (MPE) [6]. The key ideas behind the concept of MEA methods can be simply concluded as two major steps as described: 1) obtain multiple-scale time series from the original time series through a coarse-grained procedure at a scale factor of $\tau$ ( $\tau$ is the length of non-overlapping windows); 2) apply corresponding single scale entropy method to estimate complexity in each coarse-grained time series.

Recently, entropy-based approaches have been successfully applied in not only selection of dominant decomposed vectors but also fault feature extraction in applications of fault diagnosis of rotating components, such as shafts, bearings, gearboxes, and rotors. In this short paper, the utilization of entropy-based methods for fault diagnosis of rotating machinery in the recent decade is summarized, as presented in Table I. It presents a comprehensive view of entropy-based applications and functionalities regarding to fault diagnosis of rotating machinery. In addition, it concludes a variety of entropy-based techniques that can be adaptively chosen by researchers to be applied in the field of fault diagnosis for rotating machinery.

\section{Open Research Trends}

It should be pointed that feature extraction has significant effects on the efficiency and accuracy of fault detection and identification in rotating machinery. In addition, due to the fact that industrial systems are becoming more and more complex in recent decades, continuing effects are still essential to be continuously put into improving the confidence of reliability and safety of industrial process. Some challenges are therefore needed to be focused, which are listed as following:

1. Robustness of the entropy methods under various operating conditions

2. Consistency in values of similarity and parameters selected

3. Removal of the magnitude influence of the data sets

4. Enrichment and modification of the entropy techniques

5. Able to deal with non-linear and non-stationary signals

6. Capable of identifying defects with increasing severity

\section{Conclusions}

In this short paper, most commonly used entropy techniques are briefly introduced. After that, the utilization of entropy-based methods for fault diagnosis 
Table 1: A summary of recent methods for fault diagnosis of rotating machinery using entropy techniques.

\begin{tabular}{|c|c|c|c|c|c|c|c|}
\hline \multirow[t]{2}{*}{ Author } & \multirow[t]{2}{*}{ Year } & \multirow[t]{2}{*}{ Object } & \multirow{2}{*}{$\begin{array}{c}\text { Signal } \\
\text { monitored }\end{array}$} & \multirow{2}{*}{$\begin{array}{c}\text { Signal } \\
\text { processing }\end{array}$} & \multicolumn{2}{|c|}{ EEA method } & \multirow[t]{2}{*}{ classifier used } \\
\hline & & & & & Type & Role & \\
\hline $\operatorname{Bin}[7]$ & 2012 & motor & vibration & $\begin{array}{l}\text { WPT and } \\
\text { EMD }\end{array}$ & Power Energy & $\begin{array}{c}\text { vector } \\
\text { selection }\end{array}$ & ANN \\
\hline Tabrizi [8] & 2015 & bearing & vibration & $\begin{array}{l}\text { WPT and } \\
\text { EEMD }\end{array}$ & Power Energy & $\begin{array}{c}\text { vector } \\
\text { selection }\end{array}$ & SVM \\
\hline Kankar [9] & 2011 & bearing & vibration & CWT & entropy ratio & $\begin{array}{l}\text { parameter } \\
\text { selection }\end{array}$ & $\begin{array}{l}\text { SOM, SVM, } \\
\text { ANN }\end{array}$ \\
\hline $\mathrm{Gu}[10]$ & 2012 & shaft & $\mathrm{AE}$ & DWT & ShanEn & $\begin{array}{c}\text { feature } \\
\text { extraction }\end{array}$ & $\mathrm{N} / \mathrm{A}$ \\
\hline Camarena [11] & 2016 & motor & vibration & $\mathrm{N} / \mathrm{A}$ & ShanEn & $\begin{array}{c}\text { feature } \\
\text { extraction }\end{array}$ & $k$-Means \\
\hline $\mathrm{He}[12]$ & 2012 & bearing & $\mathrm{AE}$ & $\mathrm{N} / \mathrm{A}$ & $A p E n$ & $\begin{array}{c}\text { feature } \\
\text { extraction }\end{array}$ & $\mathrm{N} / \mathrm{A}$ \\
\hline Sampaio [13] & 2016 & shaft & vibration & $\mathrm{N} / \mathrm{A}$ & $A p E n$ & $\begin{array}{c}\text { feature } \\
\text { extraction }\end{array}$ & $\mathrm{N} / \mathrm{A}$ \\
\hline Lin $[14]$ & 2017 & $\begin{array}{c}\text { gear and } \\
\text { bearing }\end{array}$ & vibration & $\begin{array}{l}\text { SLA and } \\
\text { WSM }\end{array}$ & $\begin{array}{l}A p E n \text { and } \\
\text { SampEn }\end{array}$ & $\begin{array}{c}\text { feature } \\
\text { extraction }\end{array}$ & $\mathrm{N} / \mathrm{A}$ \\
\hline Liang [15] & 2015 & gearbox & $\mathrm{AE}$ & WT-EMD & SampEn & $\begin{array}{l}\text { vector } \\
\text { selection }\end{array}$ & SVM \\
\hline Wu [16] & 2016 & bearing & vibration & EMD & MSE & $\begin{array}{c}\text { vector } \\
\text { selection }\end{array}$ & decision tree \\
\hline $\operatorname{Pan}[17]$ & 2016 & motor & vibration & $\mathrm{N} / \mathrm{A}$ & MSE & $\begin{array}{c}\text { feature } \\
\text { extraction }\end{array}$ & SVM \\
\hline Verma $[18]$ & 2016 & motor & $\begin{array}{c}\text { vibration, } \\
\text { current }\end{array}$ & $\mathrm{N} / \mathrm{A}$ & MSE & $\begin{array}{c}\text { feature } \\
\text { extraction }\end{array}$ & ANN \\
\hline Aouabdi [19] & 2017 & gearbox & current & DWT & PCA-MSE & $\begin{array}{c}\text { feature } \\
\text { extraction }\end{array}$ & $\mathrm{N} / \mathrm{A}$ \\
\hline Chen [20] & 2016 & gearbox & vibration & LMD & $F u z z y E n$ & $\begin{array}{l}\text { vector } \\
\text { selection }\end{array}$ & ANFIS \\
\hline Metha [21] & 2016 & bearing & vibration & $\mathrm{N} / \mathrm{A}$ & MFE & $\begin{array}{c}\text { feature } \\
\text { extraction }\end{array}$ & VPMCD \\
\hline Zhao [22] & 2016 & bearing & vibration & EEMD & MFE & $\begin{array}{c}\text { feature } \\
\text { extraction }\end{array}$ & SVM \\
\hline Zheng [23] & 2017 & bearing & vibration & $\mathrm{N} / \mathrm{A}$ & $\begin{array}{l}\text { composite } \\
\text { MFE }\end{array}$ & $\begin{array}{c}\text { feature } \\
\text { extraction }\end{array}$ & $\begin{array}{l}\text { ensemble } \\
\text { SVM }\end{array}$ \\
\hline Wu [24] & 2012 & bearing & vibration & $\mathrm{N} / \mathrm{A}$ & MPE & $\begin{array}{c}\text { feature } \\
\text { extraction }\end{array}$ & SVM \\
\hline Vakharia [25] & 2015 & bearing & vibration & CWT & MPE & $\begin{array}{c}\text { parameter } \\
\text { selection }\end{array}$ & ANN, SVM \\
\hline Zhang [26] & 2015 & bearing & vibration & EEMD & PerEn & $\begin{array}{c}\text { vector } \\
\text { selection }\end{array}$ & SVM \\
\hline Yi [27] & 2017 & bearing & vibration & TSSA & PerEn & $\begin{array}{l}\text { vector } \\
\text { selection }\end{array}$ & $\mathrm{N} / \mathrm{A}$ \\
\hline
\end{tabular}

of rotating machinery is summarized. In addition, future trends are proposed to improve the effectiveness of entropy-based diagnostic methods. However, with increasing efforts been put into the entropy methods applied in characterizing fault information, it is believed that entropy-based techniques would be constituently applied as promising techniques in fault diagnosis of rotating machinery. 


\section{Acknowledgement}

This work is partially supported by International and Hong Kong, Macao \& Taiwan collaborative innovation platform and major international cooperation projects of colleges in Guangdong Province (No.2015KGJHZ026), The Natural Science Foundation of Guangdong Province (No.2016A030307029), and Maoming Engineering Research Center on Industrial Internet of Things (No.517018).

\section{References}

1. J. CusidÓCusido, L. Romeral, J. A. Ortega, J. A. Rosero, and A. G. Espinosa, "Fault detection in induction machines using power spectral density in wavelet decomposition," IEEE Transactions on Industrial Electronics, vol. 55, no. 2, pp. 633-643, 2008.

2. G. Xiong, L. Zhang, H. Liu, H. Zou, and W. Guo, "A comparative study on ApEn, SampEn and their fuzzy counterparts in a multiscale framework for feature extraction," Journal of Zhejiang University SCIENCE A, vol. 11, no. 4, pp. 270-279, 2010.

3. C. Bandt and B. Pompe, "Permutation entropy: a natural complexity measure for time series," Physical review letters, vol. 88, no. 17, p. 174102, 2002.

4. M. Costa, A. L. Goldberger, and C.-K. Peng, "Multiscale entropy analysis of biological signals," Physical review E, vol. 71, no. 2, p. 021906, 2005.

5. J. Zheng, J. Cheng, Y. Yang, and S. Luo, "A rolling bearing fault diagnosis method based on multi-scale fuzzy entropy and variable predictive model-based class discrimination," Mechanism and Machine Theory, vol. 78, pp. 187-200, 2014.

6. W. Aziz and M. Arif, "Multiscale permutation entropy of physiological time series," in 9th International Multitopic Conference, IEEE INMIC 2005. IEEE, 2005, pp. $1-6$.

7. G. Bin, J. Gao, X. Li, and B. Dhillon, "Early fault diagnosis of rotating machinery based on wavelet packets-Empirical mode decomposition feature extraction and neural network," Mechanical Systems and Signal Processing, vol. 27, pp. 696-711, 2012.

8. A. Tabrizi, L. Garibaldi, A. Fasana, and S. Marchesiello, "Early damage detection of roller bearings using wavelet packet decomposition, ensemble empirical mode decomposition and support vector machine," Meccanica, vol. 50, no. 3, pp. 865$874,2015$.

9. P. K. Kankar, S. C. Sharma, and S. P. Harsha, "Fault diagnosis of ball bearings using continuous wavelet transform," Applied Soft Computing, vol. 11, no. 2, pp. 2300-2312, 2011.

10. D. Gu, J. Kim, T. Kelimu, S.-C. Huh, and B.-K. Choi, "Evaluation of the use of envelope analysis and DWT on AE signals generated from degrading shafts," Materials Science and Engineering: B, vol. 177, no. 19, pp. 1683-1690, 2012.

11. D. Camarena-Martinez, M. Valtierra-Rodriguez, J. P. Amezquita-Sanchez, D. Granados-Lieberman, R. J. Romero-Troncoso, and A. Garcia-Perez, "Shannon entropy and $\mathrm{k}-$ means method for automatic diagnosis of broken rotor bars in induction motors using vibration signals," Shock and Vibration, vol. 2016, 2016.

12. Y. He and X. Zhang, "Approximate entropy analysis of the acoustic emission from defects in rolling element bearings," Journal of Vibration and Acoustics, vol. 134, no. 6, p. 061012, 2012. 
13. D. L. Sampaio and R. Nicoletti, "Detection of cracks in shafts with the approximated entropy algorithm," Mechanical Systems and Signal Processing, vol. 72, pp. 286-302, 2016.

14. J. Lin and C. Dou, "A novel method for condition monitoring of rotating machinery based on statistical linguistic analysis and weighted similarity measures," Journal of Sound and Vibration, vol. 390, pp. 272-288, 2017.

15. J. Liang and Z. Yang, "A novel wavelet transform-empirical mode decomposition based sample entropy and SVD approach for acoustic signal fault diagnosis," in International Conference in Swarm Intelligence. Springer, 2015, pp. 232-241.

16. T.-Y. Wu, C.-L. Yu, and D.-C. Liu, "On multi-scale entropy analysis of ordertracking measurement for bearing fault diagnosis under variable speed," Entropy, vol. 18, no. 8, p. 292, 2016.

17. S. Pan, T. Han, A. C. Tan, and T. R. Lin, "Fault diagnosis system of induction motors based on multiscale entropy and support vector machine with mutual information algorithm," Shock and Vibration, vol. 2016, 2016.

18. A. K. Verma, S. Sarangi, and M. Kolekar, "Misalignment faults detection in an induction motor based on multi-scale entropy and artificial neural network," Electric Power Components and Systems, vol. 44, no. 8, pp. 916-927, 2016.

19. S. Aouabdi, M. Taibi, S. Bouras, and N. Boutasseta, "Using multi-scale entropy and principal component analysis to monitor gears degradation via the motor current signature analysis," Mechanical Systems and Signal Processing, vol. 90, pp. 298$316,2017$.

20. X. Chen, G. Cheng, H. Li, and M. Zhang, "Diagnosing planetary gear faults using the fuzzy entropy of LMD and ANFIS," Journal of Mechanical Science and Technology, vol. 30, no. 6, pp. 2453-2462, 2016.

21. P. Mehta, J. A. Gaikwad, and J. V. Kulkarni, "Application of multi-scale fuzzy entropy for roller bearing fault detection and fault classification based on VPMCD," in Recent Trends in Electronics, Information 8 Communication Technology (RTEICT), IEEE International Conference on. IEEE, 2016, pp. 256-261.

22. H. Zhao, M. Sun, W. Deng, and X. Yang, "A new feature extraction method based on EEMD and multi-scale fuzzy entropy for motor bearing," Entropy, vol. 19, no. 1, p. 14, 2016.

23. J. Zheng, H. Pan, and J. Cheng, "Rolling bearing fault detection and diagnosis based on composite multiscale fuzzy entropy and ensemble support vector machines," Mechanical Systems and Signal Processing, vol. 85, pp. 746-759, 2017.

24. S.-D. Wu, P.-H. Wu, C.-W. Wu, J.-J. Ding, and C.-C. Wang, "Bearing fault diagnosis based on multiscale permutation entropy and support vector machine," Entropy, vol. 14, no. 8, pp. 1343-1356, 2012.

25. V. Vakharia, V. Gupta, and P. Kankar, "A multiscale permutation entropy based approach to select wavelet for fault diagnosis of ball bearings," Journal of Vibration and Control, vol. 21, no. 16, pp. 3123-3131, 2015.

26. X. Zhang, Y. Liang, J. Zhou et al., "A novel bearing fault diagnosis model integrated permutation entropy, ensemble empirical mode decomposition and optimized SVM," Measurement, vol. 69, pp. 164-179, 2015.

27. C. Yi, Y. Lv, M. Ge, H. Xiao, and X. Yu, "Tensor singular spectrum decomposition algorithm based on permutation entropy for rolling bearing fault diagnosis," Entropy, vol. 19, no. 4, p. 139, 2017. 